\title{
SEROPREVALENCE AND CLINICAL CORRELATES OF TOXOPLASMA GONDII INFECTION AMONG INFANTS IN TERTIARY CARE HOSPITAL
}

Gohel Tejash ${ }^{1}$, Dilip T2 ${ }^{2}$, Sujata B ${ }^{3}$

\section{HOW TO CITE THIS ARTICLE:}

Gohel Tejash, Dilip T, Sujata B. "Seroprevalence and Clinical Correlates of Toxoplasma Gondii Infection among Infants in Tertiary Care Hospital". Journal of Evolution of Medical and Dental Sciences 2014; Vol. 3, Issue 46, September 22; Page: 11198-11203, DOI: 10.14260/jemds/2014/3460

ABSTRACT: BACKGROUND: Toxoplasmosis is caused by the infection with protozoan parasite Toxoplasma gondii. A cute infection in pregnant women may be transmitted to fetus and cause severe illness. Most infected new born have no symptoms at birth, but if left untreated serious clinical manifestation can develop during childhood and early adulthood. Because congenital toxoplasma infection does not usually produce recognizable sign of infection in infancy and non-specificity of the symptoms, we were concerned by the fact that most case remain untreated, therefore we have used IgM avidity ELISA for screening infants, and identify who should receive therapy. MATERIAL AND METHODS: A total of 90 infants were included in the study. The group consists of infants with mother of $\mathrm{BOH}$, and clinical conditions suggestive of Toxoplasmosis. Blood sample collected from all these infants and were screened by ELISA for IgM antibodies. RESULTS: Among 90 infants 2 were seropositive for IgM toxoplasmosis, both presented with chorioretinitis. CONCLUSION: Congenital toxoplasmosis is a preventable disease and it emphasize the importance of early prenatal serological tests, and preventive measures when necessary, in order to avoid a dramatic fetal disease. It should be mandatory to screen every immune compromised patient, pregnant females and infants for toxoplasmosis, and initiation of judicious treatment on time can, thus be provided to prevent morbidity and mortality due to toxoplasmosis.

KEYWORDS: Toxoplasmosis, Infants, Serology, IgM ELISA.

INTRODUCTION: Toxoplasmosis is one of the most common parasitic infections seen in humans. Approximately one third of the population is exposed to this parasite, while it is dangerous for immune compromised patients, mothers infected during pregnancy and infants. ${ }^{1}$ Toxoplasmosis is usually diagnosed by serological tests by detection of specific IgM and IgG antibodies. A positive IgM titer establishes recent infection whereas negative IgM result virtually rules out recently acquired infection. ${ }^{1}$

Acute infection with Toxoplasma during pregnancy and its potentially tragic outcome for the fetus continues to occur worldwide despite the fact that it can be prevented worldwide. ${ }^{2}$ The sero prevalence in pregnant women on world wide scale varies from $7-51.3 \% .{ }^{3}$ Congenital Toxoplasmosis in newborns is an important cause of morbidity and mortality.

It is generally subclinical but infected infants are at the risk of developing hydrocephalus, microcephalus, chorioretinitis, and intracranial calcifications. Toxoplasma specific IgM antibody, which does not cross the placenta, is considered to be the good marker of congenital infection. Thus the present study was conducted to determine the seroprevalence and clinical correlates of Toxoplasma gondii infection in infants. 
MATERIAL METHODS: After obtaining Institutional Ethical Committee approval the present clinical, prospective study of sero prevalence and clinical correlation of Toxoplasma gondii infection, was carried out in Department of Microbiology a Tertiary care Institute, during the period December 2011 to October 2013.

Total of 90 infant's indoor as well as outdoor patients referred from Obstetricians, Pediatricians who were having strong index of clinical and/or radiological suspicion for Toxoplasmosis infection were included in our study. The relevant history, clinical findings and investigations were noted. Exclusion criteria comprised of patients who were not willing to participate in the study.

METHODOLOGY: The study participants were explained about the study protocol and involved tests in the language of their understanding. After the informed consent they were enrolled for this study. Approximately 5 to $6 \mathrm{ml}$ blood was collected under all aseptic precautions and it was then labeled correctly and was centrifuged at 3000 rotation per minute for ten minutes. Serum was transferred in the sterile labeled vials and these were stored at $-20^{\circ} \mathrm{C}$. Before performing the ELISA the samples and ELISA kit was brought to the room temperature:

1) Test Details4: Name of the test used: Enzyme linked immune sorbant assay (Enzy well Toxoplasma IgM - Diesse - Italy)

2) Principle of the test: The test for the assay of Toxoplasma IgM is based on the principle of the capture of these immunoglobulins and the subsequent identification of those which are specific, making use of their ability to bind an antigen conjugated to peroxidase. The capture is performed using monoclonal antibodies bound to the solid phase (microtiter wells). The antigen is composed of purified, inactivated and sonicated tachyzoite labelled with peroxidase bound to specific and anti-toxoplasma monoclonal antibodies.

3) Procedure: Bring the kit and sample at room temperature before start of the procedure. Prepare the required number of strip.

Prepare the washing buffer by diluting the wash buffer $10 x\left(100 \mathrm{ml}+900 \mathrm{ml} \mathrm{H}_{2} \mathrm{O}\right)$. Prepare the immune complex by adding the conjugate to the antigen (volume shown on the label). Dilute samples 1:101 distributing 10microlitre of serum into $1 \mathrm{ml}$ of diluents. Dispense $100 \mathrm{microlitre}$ of each diluted sample per well. Place UNDILUTED control in a strip (100microlitre in each well).

The minimum requisite is 1 negative control, 2 cut off, 1 positive control. Leave one well for blank, performed using 100 microlitre of substrate mixture. Wells are covered with protective film and incubated for 45 minutes at $37^{\circ} \mathrm{C}$.

After washing four times for 30 seconds (300microlitre), add 100 microliter of immune complex (Antigen- anti Toxoplasma gondii monoclonal antibodies labeled with peroxidase) to each well and incubate again for 45 minutes at $37^{\circ} \mathrm{C}$, covering the well with the protective film.

The plate is washed again 4 times as described above. Finally, substrate is distributed 100 microlitre/well and incubated for 15 minutes at room temperature.

After 15 minutes at room temperature the enzymatic reaction is stopped by adding 100 microlitre of stop solution. The absorbance (O. D.) is read at $450 \mathrm{~nm}$ or $450 / 620 \mathrm{~nm}$ within 30 minutes. 


\section{SCHEME OF TEST PROCEDURE:}

Step 1: Place 100 micro litre of diluted sample/controls in the wells of the strips.

Incubate for $45 \mathrm{~min}$ at $37^{\circ} \mathrm{C}$

Wash 4 times (300 micro litre).

Step 2: Add 100 micro litre of immune complex to each well.

Incubate for $45 \mathrm{~min}$. at $37 \mathrm{oC}$

Wash 4 times (300 micro litre).

Step 3: Add 100 micro litre of substrate to each well.

Incubate for $15 \mathrm{~min}$. at room temperature.

Step 4: Add 100 micro litre of stop solution.

Read absorbance at $450 \mathrm{~nm}$ within $30 \mathrm{~min}$.

4) Test validation: Subtract the value of the blank $(\leq 0.150)$ from all other readings. The O.D. values of the control Cut-off serum tested in triplicate must be within $25 \%$ of the mean value. Disregard any abnormal value and recalculate the mean. The Positive control must have an O.D.at least 1.5 times that of cut-off serum. The ratio between Negative control and cut-off must be $\leq 0.6$. The O.D. Cut-off must be $\geq 0.2$ at $450 \mathrm{~nm}$ and 0.16 at $\geq 450 / 620 \mathrm{~nm}$.

5) If the absorbance of the sample is higher than that of cut-off, the sample is positive for the presence of specific IgM. Calculate the ratio between the O.D. value of the sample and that of the cut-off:

- The sample is considered.

- Positive, if the ratio is $>1.2$.

- Negative, if the ratio is $<0.8$.

- Doubtful, +/- $20 \%$ of cut-off.

6) Interpretation of results: ELISA test was put for detection of IgM antibodies and its level for Toxoplasma gondii infection. Presence of IgM antibodies does indicate on going current infection which may range from last 7 to 10 days. Positive and Negative findings of ELISA were correlated with clinical findings and/or radiological findings. Data were recorded in the proforma and analysed statistically by using student ' $t$ ' test, standard error of difference between two means and Chi-square test. The SPSS version model was used. $\mathrm{p}<0.05$ was considered as statistically significant and $\mathrm{p}<0.01$ was considered as highly significant.

\section{RESULTS:}

\begin{tabular}{|c|c|c|c|}
\hline \multirow{2}{*}{ Age (Months) } & \multicolumn{2}{|c|}{ Gender } & Number of \\
& Male & Female & Cases (\%) \\
\hline$\leq 1$ & 4 & 4 & $8(8.88 \%)$ \\
\hline$>1$ to 2 & 7 & 0 & $7(7.77 \%)$ \\
\hline$>2$ to 4 & 10 & 4 & $14(15.55 \%)$ \\
\hline$>4$ to 6 & 6 & 3 & $9(10 \%)$ \\
\hline$>6$ to 8 & 8 & 7 & $15(16.66 \%)$ \\
\hline$>8$ to 10 & 10 & 5 & $15(16.66 \%)$ \\
\hline$>10$ to 12 & 17 & 5 & $22(24.44 \%)$ \\
\hline Total & $\mathbf{6 2 ( 6 8 . 8 8 \% )}$ & $\mathbf{2 8 ( 3 1 . 1 1 \% )}$ & $\mathbf{9 0 ( 1 0 0 \% )}$ \\
\hline
\end{tabular}

Table 1: Age- Wise distribution of patients in infants group 
Maximum age group was from >10 to 12 months i.e., 22 (24.44\%).Ratio of male to female is 2.21.

\begin{tabular}{|l|c|c|c|}
\hline \multicolumn{1}{|c|}{$\begin{array}{c}\text { Clinical } \\
\text { presentation }\end{array}$} & $\begin{array}{c}\text { IgM Positive } \\
\text { (\%) }\end{array}$ & $\begin{array}{c}\text { IgM Negative } \\
\text { (\%) }\end{array}$ & $\begin{array}{c}\text { Number } \\
\text { of cases (\%) }\end{array}$ \\
\hline $\begin{array}{l}\text { Chorioretinitis / } \\
\text { visual loss }\end{array}$ & $2(2.22 \%)$ & $40(44.44 \%)$ & $42(46.66 \%)$ \\
\hline Hydrocephalus & 0 & $13(13.33 \%)$ & $12(13.33 \%)$ \\
\hline Seizures & 0 & $10(11.11 \%)$ & $10(11.11 \%)$ \\
\hline Hepatosplenomegaly & 0 & $31(34.44 \%)$ & $31(34.44 \%)$ \\
\hline Thrombocytopenia & 0 & $13(14.44 \%)$ & $13(14.44 \%)$ \\
\hline Anaemia & 0 & $20(22.22 \%)$ & $20(22.22 \%)$ \\
\hline
\end{tabular}

Table 2: Clinical Presentations in infants

Out of 90 infants 2 were positive for toxoplasma $\operatorname{IgM}$ and chorioretinitis was the commonest sign.

\begin{tabular}{|c|c|}
\hline $\begin{array}{c}\text { Age } \\
\text { (months) }\end{array}$ & $\begin{array}{c}\text { IgM Positive } \\
\text { (\%) }\end{array}$ \\
\hline$\leq 1$ & 0 \\
\hline$>1-2$ & 0 \\
\hline$>2-4$ & 0 \\
\hline$>4-6$ & $1(1.11 \%)$ \\
\hline$>6-8$ & 0 \\
\hline$>8-10$ & 0 \\
\hline$>10-12$ & $1(1.11 \%)$ \\
\hline Table 3: Seroprevalence of IgM \\
Toxoplasmosis in infants (n=2)
\end{tabular}

$2(2.22 \%)$ were positive for IgM Toxoplasma of which one each from age group of $>4-6$ months and $>10-12$ months.

DISCUSSION: In infants transmission increases with increase in gestational age however the severity of congenital disease decreases with increasing gestational age. Although these infants appear healthy at birth, they may develop clinical symptoms and deficiencies later in life. 5

In our study maximum infants were falling between the age range of 10-12 months i.e. 22 $(24.44 \%)$ cases followed by $15(16.66 \%)$ cases each form the age range of $>6-8$ months and $>8-10$ months (Table 1), and male infants to female infants ratio was 2.21:1. However in study by Nicholas G. Guerina et $\mathrm{al}^{5}$ found that male infants to female infants ratio in suspected cases was 1:1.

A study conducted by Eichenwald HF, ${ }^{6}$ found that 94 out of 108 infants developed chorioretinitis in congenital toxoplasmosis, also study by Maria Aptouramani et al, ${ }^{7}$ found that chorioretinitis was the most prominent manifestations, occurring in 5(50\%) symptomatic cases. 
However in study by Nicholas G Guerina et $\mathrm{al}^{5}$ and R E Gilbert et al ${ }^{8}$ chorioretinitis in infants was found in $4 \%$ and $10 \%$ in suspected cases respectively.

However in our study both 2 cases positive for IgM Toxoplasma presented with chorioretinitis as common manifestation. The frequency of vertical transmission increases with the gestational age. In contrast, severity of the infection depends on how early in the gestational life the infection is acquired.

Although the majority of infants appear to be healthy at birth, significant long term sequelae may become obvious only months or years later. ${ }^{2}$ However In study conducted by Eurico Camargo Neto et $\mathrm{al}^{9}$ and Jorge Enrique Gomez-Marin et $\mathrm{al}^{10} \mathrm{IgM}$ seropositivity was found to be $0.19 \%$ and $0.39 \%$ respectively. However in our study IgM seropositivity was found to be $2(2.22 \%)$ (Table no 8). Also on analyzing the history of the mothers of IgM positive infants, it was found that one of the mothers was toxoplasma positive during pregnancy.

CONCLUSION: Congenital toxoplasmosis is a preventable disease and it emphasize the importance of early prenatal serological tests, and preventive measures when necessary, in order to avoid a dramatic fetal disease. There is considerable variation in the seropositivity among the women of child bearing age in different geographical areas and also depends on sensitivity of various kits used. It should be mandatory to screen every immune compromised patient, pregnant females and infants for toxoplasmosis, and initiation of judicious treatment on time can, thus be provided to prevent morbidity and mortality due to toxoplasmosis.

\section{REFERENCES:}

1. Sarkar M D, Anuradha B, Sharma N \& Roy R N. Seropositivity of toxoplasmosis in antenatal women with bad obstetric history in a tertiary care hospital of Andhra Pradesh. India Health Popul Nutr.2012 March; 30 (1): 37-92.

2. Jose G. Montoya \& Jack S. Remington Management of Toxoplasma gondii infection during pregnancy, Clinical Infectious Diseases 2008; 47:554-66.

3. Kumar A, Arora V, Mathur M. Toxoplasma antibody level in female with habitual or sporadic abortion and normal pregnancies, Indian journal of medical microbiology, (2004) 22 (4): 276-277.

4. Prodotto da/manufactured by/Fabricadopor: Rif. I,O - 09/013 - inf. Tecn. - Ed. 16.06.2010.

5. Guerina NG, Hsu HW, Meissner HC, Maguire JH, Lynfield R, Stechenberg B, et al. Neonatal Serological Screening and Early Treatment for Congenital Toxoplasma Gondii Infection. N Engl J Med 1994 Jun 30; 330 (26): 1858-63.

6. Eichenwald H F (1960), A Study of Congenital Toxoplasmosis with particular emphasis on clinical manifestation, sequelae and therapy In:Slim JC ,Editor. Human toxoplasmosis. Munsgaard, Copenhagen, pp: 41-49.

7. Aptouramani $\mathrm{M}$, Theodoridou $\mathrm{M}$. et al, A dedicated surveillance network for congenital toxoplasmosis in Greece, 2006-2009: assessment of the results. http://www.biomedcentral.com/1471-2458/12/1019/prepub.

8. Gilbert R E, Peckham C S. Congenital toxoplasmosis in United Kingdom: to screen or not to screen? J Med Screen 2002; 9: 135-141. 


\section{ORIGINAL ARTICLE}

9. Neto E C, Rubin R, Schulte J S, Giugliani R. New born screening for congenital Infectious diseases, Emerging Infectious Diseases June 2004; 10(6) : p1069-1073.

10. Jorge Enrique - Gomez Marin, Alejandra de-la -Torre et al First Colombian multi centric new born screening for congenital Toxoplasmosis PLOS Neglected Tropical Diseases. May 2011; 5 (5); 1195.p; 1-10.

\section{AUTHORS:}

1. Gohel Tejash

2. Dilip T.

3. Sujata B.

\section{PARTICULARS OF CONTRIBUTORS:}

1. MD Microbiology, Department of Microbiology, LTMMC, Sion, Mumbai.

2. Additional Professor, Department of Microbiology, LTMMC, Sion, Mumbai.

3. Professor and HOD, Department of Microbiology, LTMMC, Sion, Mumbai.

\section{NAME ADDRESS EMAIL ID OF THE} CORRESPONDING AUTHOR:

Dr. Gohel Tejash,

Yamuna Kunj,

Opposite Lavhekar Hospital,

Kailash Nagar, Nanded-431605,

Maharashtra.

Email: goheltd@rediffmail.com

Date of Submission: 30/08/2014.

Date of Peer Review: 01/09/2014.

Date of Acceptance: 12/09/2014.

Date of Publishing: 20/09/2014. 